\title{
Antenatal diagnosis of alobar holoprosencephaly
}

\author{
Dolly Khanna ${ }^{1}$, Karandeep S. Bhatti ${ }^{2 *}$
}

\author{
${ }^{1}$ Department of Radiodiagnosis, Surjit Hospital, Amritsar, Punjab, India \\ ${ }^{2}$ Department of Medicine, Mrs. Khushbir Kalra Memorial Hospital, Amritsar, Punjab, India
}

Received: 29 February 2020

Accepted: 30 March 2020

\section{*Correspondence:}

Dr. Karandeep Singh Bhatti,

E-mail: karandeepsinghbhatti22@gmail.com

Copyright: (C) the author(s), publisher and licensee Medip Academy. This is an open-access article distributed under the terms of the Creative Commons Attribution Non-Commercial License, which permits unrestricted non-commercial use, distribution, and reproduction in any medium, provided the original work is properly cited.

\begin{abstract}
Holoprosencephaly (HPE), a congenital induction disorder, occurs due to failed segmentation of neural tube and subsequent incomplete separation of the prosencephalon. Because of the defect in the ventral induction, HPE is also associated with multiple facial abnormalities. Mortality correlates with the severity of brain malformation and facial phenotype. Frequent causes of death include respiratory infections, dehydration due to uncontrolled diabetes insipidus, intractable seizures, and brainstem malfunction. This is a case of Alobar holoprosencephaly in the fetus of a 31-year-old G2P1 female, detected on level II obstetric ultrasound at 17 weeks of gestation. The objective of this case report is to discuss the etiology, pathogenesis, prenatal sonographic findings, management and prognosis of HPE which can aid in its early antenatal diagnosis and can help formulate an adequate plan for the parents and fetus.
\end{abstract}

Keywords: Alobar, Antenatal, Fused thalami, Holprosencephaly, Monoventricle, Ultrasonography

\section{INTRODUCTION}

Holoprosencephaly (HPE) is an abnormality of brain development in which the brain does not divide properly into the right and left hemispheres. There are 4 types of HPE, distinguished by severity. From most to least severe, the 4 types are alobar, semi lobar, lobar and middle interhemispheric variant (MIHV). ${ }^{1}$

HPE occurs between the $18^{\text {th }}$ and $28^{\text {th }}$ day of gestation, indicating that it is a disorder of gastrulation. ${ }^{2}$

HPE is estimated to occur in 1 in 16000 live births. ${ }^{2}$

This is a case of Alobar holoprosencephaly in the fetus of a 31-year-old G2P1 female, detected on Level II obstetric ultrasound at 17 weeks of gestation.

\section{CASE REPORT}

A 31-year-old G2 P1 female came to the department for her level II obstetric ultrasonography.
The sonogram showed single live fetus, consistent with 17 weeks gestation, with variable presentation at the time of study and normal fetal movements.

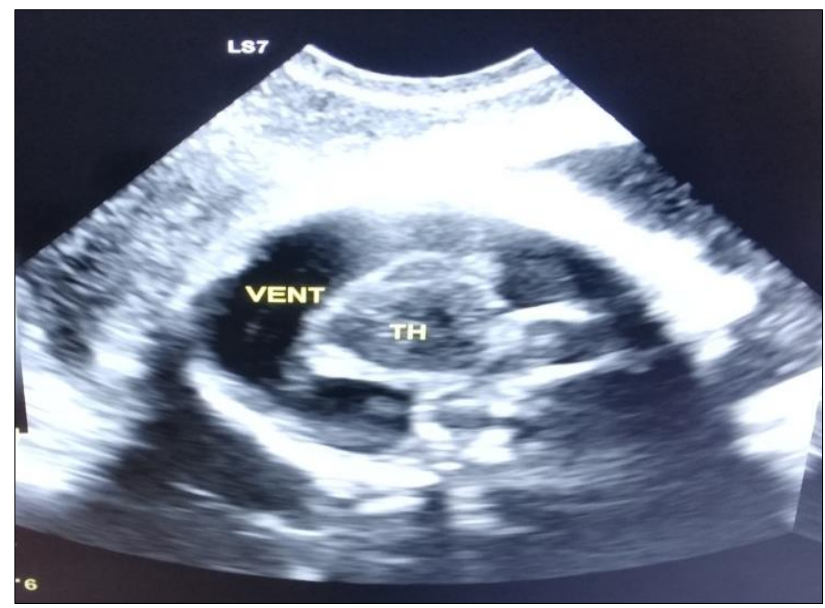

Figure 1: The fetal brain showed fused thalami and mono-ventricle. 


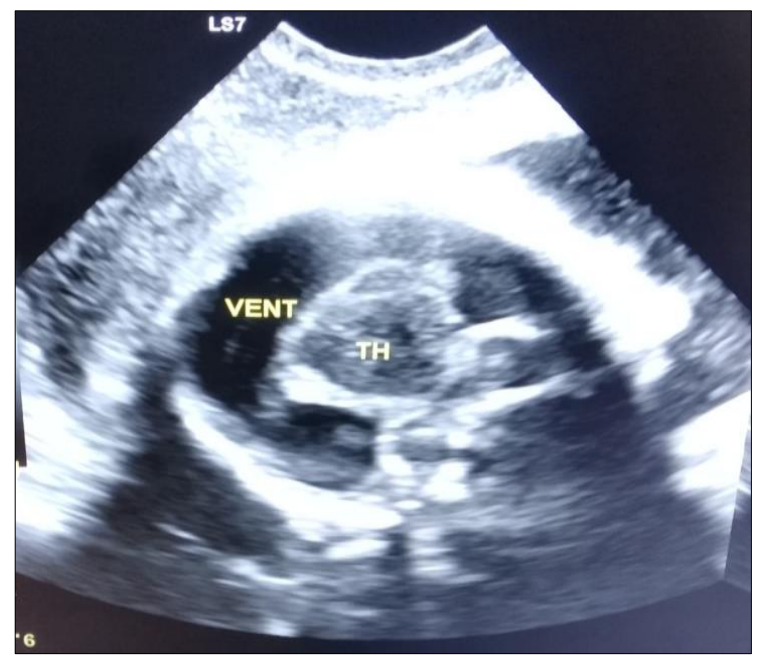

Figure 2: Presence of mono-nostril.

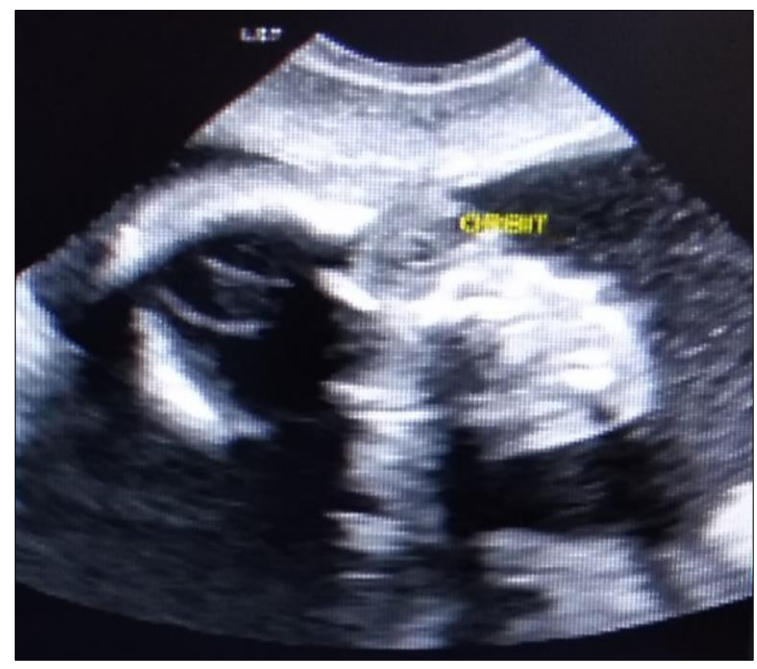

Figure 3: Presence of only one small sized orbit.

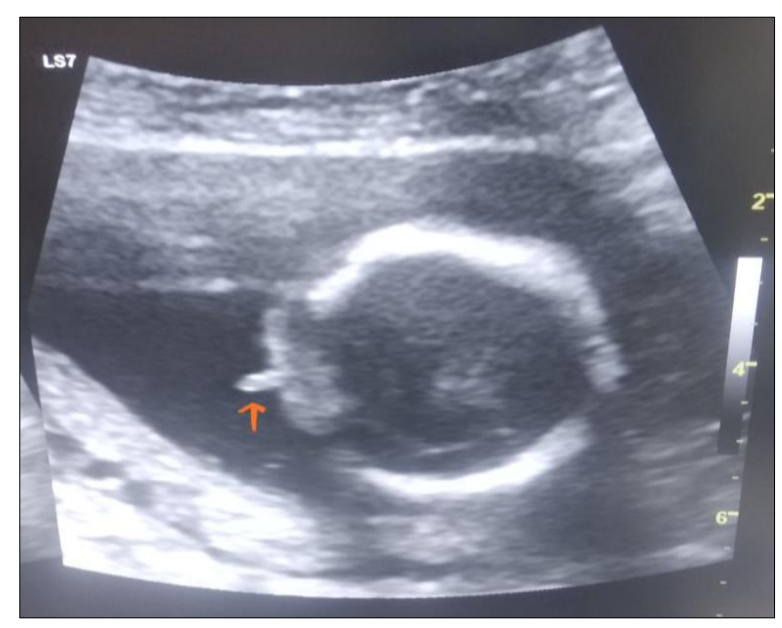

Figure 4: Presence of proboscis.

The fetal brain showed fused thalami and mono-ventricle (Figure 1). Fetal midface showed presence of mono- nostril (Figure 2). There was only one small sized orbit (Figure 3). Proboscis could be seen (Figure 4).

The cerebral tissue was confined to anterior basicranium. There was absence of cavum septum pellucidum. The cerebellum showed generalized hypoplasia. The fetal chest and abdomen appeared normal. The fetal heart was normal sized, four chambered, with the apex formed by left ventricle. The fetal anterior abdominal wall was intact. Fetal stomach and bladder were well visualized. No fetal mass lesion was identified. There was no definite evidence of renal pyelectasis.

The fetal extremities appeared normal to the visualized extent. Fetal growth parameters such as biparietal diameter, Head circumference, abdominal circumference and Femur length were $3.66 \mathrm{~cm}$ (17 weeks, 5 days), 12.19 cm (16 weeks 1 day), $12.66 \mathrm{~cm}$ (18 weeks 2 days) and $2.71 \mathrm{~cm}$ (18 weeks 2 days) respectively. Other fetal parameters such as nuchal fold, cisterna magna, and trans cerebellar diameter were measured to be $1.4 \mathrm{~mm}, 3.8 \mathrm{~mm}$ and $14.2 \mathrm{~mm}$ respectively. The patient has been asked for a regular follow up to decide upon the continuation of pregnancy and forming an adequate management plan.

\section{DISCUSSION}

HPE is a congenital induction disorder of the brain occurring at 3-6 weeks gestation, with failed segmentation of neural tube. This leads to incomplete separation of the prosencephalon. ${ }^{3}$

DeMyer and Zeman suggested that this resulted from a defect in the ventral induction and from the patterning of the rostral neural tube by the prechordal mesenchyme. As ventral induction is related to facial development, many HPE cases also demonstrate craniofacial abnormalities leading to so called "holoprosencephaly sequence". ${ }^{2}$

\section{HPE is classified into 4 types}

1. Alobar, which means the complete absence of division of the prosencephalon structures, resulting in completely absent interhemispheric fissure and corpus callosum, fused thalami, fused cerebral hemispheres with only one cerebral ventricle, and facial dysmorphism which include such abnormalities as cyclopia, proboscis, ethmocephaly and cebocephaly. It is the most severe form.

2. Semilobar, consisting in incomplete separation of cerebral hemispheres: there are 2 cerebral hemispheres connected in the frontal area, with a singlular ventricular cavity and partially fused thalami.

3. Lobar, in this case interhemispheric fissure is present, septum pellucidum is absent and frontal horns of lateral ventricles communicate freely, corpus callosum is absent, hypoplastic or normal, with midline fusion of cingulated gyrus. It is the least severe from. 
4. MIVH (middle Interhemispheric variant), which means a defect of separation of the posterior portions of the frontal lobes and the parietal lobes, with varying lack of cleavage of the basal ganglia and thalami and absence of the body of the corpus callosum but the presence of the genu and splenium of the corpus callosum. ${ }^{4}$

Studying HPE on a molecular level; has led to the identification of the HPE genes: Sonic hedgehog (SHH), ZIC2 and SIX3. To date, at least 12 loci located on 11 different chromosomes contain genes involved in HPE. For 5 of them, a minimal critical region has been identified: HPE 1 at 21q22.3, HPE 2 at 2p21, HPE 3 at $7 \mathrm{q} 36$, HPE 4 at $18 \mathrm{p}$, and HPE 5 at $13 \mathrm{q} 32 .^{2}$

Multiple environmental factors have also been reported in the pathogenesis of HPE, including: maternal diabetes, a 200 folds increase in the incidence of HPWE in babies of diabetic mothers was reported; radiation or toxin exposure during pregnancy; TORCH infection, cigarette smoking; and retinoic acid. ${ }^{5}$ The HPE facies which are characterized by hypotelorism, are grouped into 5 major categories: (1) cyclopia, a single eye or partially divided eyes in a single orbit with a proboscis above the eye; (2) ethmocephaly, severe hypotelorism and a proboscis between the eyes; (3) cobocephaly, hypotelorism with a single nostril and a blinded nose; (4) absent intermaxillary segment with central defect and hypotelorism (5) intermaxillary rudiment with hypotelorism. ${ }^{5}$

In general, mortality correlates positively with the severity of the brain malformation and, by extension, severity of the facial phenotype. In contrast to most children with Alobar HPE, children with HPE types other than Alobar may more often survive into adulthood. Frequent causes of death include respiratory infections, dehydration secondary to uncontrolled diabetes insipidus, intractable seizures, and sequelae of brainstem malfunction, including aberrant control of respiration and heartrate. ${ }^{6}$

\section{CONCLUSION}

In summary, HPE is a major malformation of the central nervous system that should be distinguished from other causes of fetal hydrocephalus. Awareness of the sonographic findings associated with HPE should improve the scope of prenatal diagnosis. Identification of concurrent facial malformations can help predict subsequent fetal outcome.

Funding: No funding sources

Conflict of interest: None declared

Ethical approval: Not required

\section{REFERENCES}

1. Rarediseases.info.nih.gov. Holoprosencephaly, Genetic and Rare Diseases Information Center (GARD) - an NCATS Program, 2020. Available at: https://rarediseases.info.nih.gov/diseases/6665/holop rosencephaly/cases/27877. Accessed on $27^{\text {th }}$ February 2020

2. Ionescu C, Calin D, Navolan D, Matei A, Dimitriu M, Herghelegiu C, Ples L. Alobar holoprosencephaly associated with a rare chromosomal abnormality, 2020

Available at: https://www.ncbi.nlm.nih.gov/pmc/articles/PMC608 6508/. Accessed on $28^{\text {th }}$ February 2020.

3. Emedicine.medscape.com. Holoprosencephaly: practice essentials, anatomy, pathophysiology. 2020. Available at: https://emedicine.medscape.com /article/2060996-overview. Accessed on $27^{\text {th }}$ February 2020.

4. Poenaru MO, Vilcea ID, Marin A. Holoprosencephaly: two case reports. Rom J Med Pract. 2012;7(1):58-62.

5. Essa AA, Feleke LA, Ahmed DM. Semilobar holoprosencephaly with cebocephaly associated with maternal early onset preeclampsia: a case report. J Med Case Reports. 2018;12(1):207.

6. Raam MS, Solomon BD, Muenke M. Holoprosencephaly: a guide to diagnosis and clinical management. Indian Pediatr. 2011;48(6):457.

Cite this article as: Khanna D, Bhatti KS. Antenatal diagnosis of alobar holoprosencephaly. Int J Reprod Contracept Obstet Gynecol 2020;9:2184-6. 